\title{
Homology modeling and molecular dynamics of $\beta$-defensin II variants in Amazonian sheep
}

\author{
A.S. Siqueira', B.B. de Souza', A.R.J. Lima', E.M. Barbosa' ${ }^{2}$, J.S.N. Azevedo ${ }^{3}$, \\ E.C. Gonçalves ${ }^{1}$ and E. Silva Filho ${ }^{2}$ \\ ${ }^{1}$ Laboratório de Tecnologia Biomolecular, Instituto de Ciências Biológicas, \\ Universidade Federal do Pará, Belém, PA, Brasil \\ ${ }^{2}$ Centro de Pesquisa de Caprinos e Ovinos do Pará, \\ Instituto de Saúde e Produção Animal, Universidade Federal Rural da Amazônia, \\ Belém, PA, Brasil \\ ${ }^{3}$ Universidade Federal Rural da Amazônia, Capanema, PA, Brasil \\ Corresponding author: E.S. Filho \\ E-mail: silva.filho@ufra.edu.br
}

Genet. Mol. Res. 15 (1): gmr.15017469

Received August 18, 2015

Accepted October 26, 2015

Published January 29, 2016

DOI http://dx.doi.org/10.4238/gmr.15017469

ABSTRACT. $\beta$-defensins are capable of creating pores in the bacterial membrane. In this study, we aim to determine the structure of 3 different sheep $\beta$-defensin 2 (SBD-2) sequences by molecular modeling. A herd of 47 sheep from the Centre for Ovine and Caprine Research of Pará was selected for this investigation. The AA, AG, and GG alleles were found on $\beta$-defensin sequences. We used homology modeling and molecular dynamic simulations to generate 3D models of peptides and they were successfully validated. The proteins are structurally very similar to classic defensins composed of $3 \beta$-sheets and 3 disulfide bonds. Variations in the organization of the tertiary structure and distribution of charged residues were found between AA, AG, and GG alleles. In this study, we were able to characterize and show the structure of 3 SBD-2 gene variants for the first time in Amazonian sheep. Results demonstrated that these variants are similar in structures to classic 
$\beta$-defensins, but contain more positives charges, which may indicate an increase in efficacy.

Key words: Antimicrobial peptide; Sheep (ovine); Defensin; Homology modeling; Molecular dynamics

\section{INTRODUCTION}

The innate immune system is the first line of defense against a wide variety of microorganisms, as it works to prevent pathogen reproduction (Janeway and Medzhitov, 2002). In the Amazon region, due to the high humidity, a wide variety of pathogenic organisms exist, which makes animal production a challenge (Casseb et al., 2013). According to local breeders, the most common diseases among flocks are caseous lymphadenitis, infectious pododermatitis, ovine brucellosis, and mastitis.

Various proteins in the innate immune system are involved in activities against pathogenic microorganisms. Among these, toll-like receptors and defensin peptides are the most prominent (Laube et al., 2006). There are three types of defensins (alpha, beta and theta), which are classified according to their structure, size and disulfide bond patterns (Selsted and Ouellette, 2005). Defensins are produced by epithelial tissues and leukocytes, and act to neutralize endotoxin activity, induce chemotaxis, inhibit the complement system, and aid in opsonization as well as in other functions (Soehnlein, 2009). Two types of $\beta$-defensin are described in sheep, SBD-1 and SBD-2 (Huttner et al., 1998a). The SBD-2 gene is found on the 26th chromosome, and consists of two exons (exon I has 58 bp and exon II has 296 bp) of approximately 1800 bp in length (Huttner et al., 1998b). SBD-2 contains a total of 64 amino acids. Monteleone et al. $(2010,2011)$ discovered an SNP in the 1659th position of the gene ( $G$ to $A$ ), which substitutes the 42 nd amino-acid arginine for lysine.

$\beta$-defensins are capable of creating toroidal pores in the bacterial membrane. In the case of anionic membranes, a transmembrane oligomeric $\beta$-barrel is formed. In membranes that contain cholesterol, $\beta$-sheet aggregation takes place on the membrane surface (Tang and Hong, 2009). Structurally, $\beta$-defensins are small cationic proteins of 3 to $5 \mathrm{kDa}$ in size. They contain of three disulphide bonds that occur between cysteines 1-5, 2-4 and 3-6. These disulphide bonds are fundamental for the maintenance of the $3 \beta$-sheets that have between 38 and 42 amino-acid residues. $\beta$-defensins are secreted via epithelial mucous into the eyes, skin, and mouth as well as in the genitourinary and respiratory systems (Zhao and Lu, 2014).

The aim of this investigation was to determine and evaluate the structure of 3 different $\beta$-defensin II polypeptide sequences found in sheep reared in the Amazon region of Brazil.

\section{MATERIAL AND METHODS}

\section{Samples and sequencing}

A herd of 47 sheep from the Centre for Ovine and Caprine Research of Pará (Belém, PA, Brazil) was used for this investigation. Blood samples were collected for DNA extraction (phenolic method). PCRs for the $\beta$-defensin gene were carried out (Monteleone et al., 2011; Souza et al., 2015), and the products were sequenced via the BIG DYE method (Life Technology) using the ABI 3500XI automatic DNA sequencer (Applied Biosystem). The sequences were aligned using the sequence provided by GenBank as a reference (U75251.1). 


\section{Construction and validation of models}

Target sequence alignment was carried out using protein sequences deposited in the Protein Data Bank (PDB) (Berman et al., 2000), and a template for the construction of the models was obtained. The structure consisted of bovine $\beta$-defensin (PDB:1BNB) with 38 amino-acid residues. It was resolved by Nuclear Magnetic Resonance, and was observed to share approximately $65 \%$ identity with the target sequences (Zimmermann et al., 1995). Initial alignment of the sequences obtained using the template sequence presented a portion with an identity corresponding to a peptide signal indicated by the SignalP server (Petersen et al., 2011). This portion was then removed in order to obtain the functional structure of defensin. For each defensin variant (AA, $A G$, GG), 100 models were constructed using the Modeller 9.14 software (Eswar et al., 2006). Spatial restrictions were applied to ensure that the best model of each defensing was selected according to DOPE energy. The quality of these models was evaluated according to 3D alignment and energy via the Root Mean Square Deviation (RMSD) and Atomic Non-Local Environment Assessment (Arnold et al., 2006).

\section{Molecular dynamics}

The $\mathrm{H}^{++}$server was used to prepare the structures for Molecular Dynamics (MD). The $\mathrm{pH}$ level was set at 7.0, and standard parameters were set for the protonation of proteins. The tools included in the AMBER 12 programme package were used for system set up, preparation and solvation, heating and molecular dynamics, as well as setting the parameters for energy minimization, (Case et al., 2012), with gaff and ff99SB force fields. Each defensin, once protonated, was solvated with water model TIP3P in a box measuring $10.0 \AA$ in each direction from the solute. $\mathrm{Cl}^{-}$ions were added in each system for charge neutralization so that topology files and coordinates could be generated. All systems proceeded to the minimization stage with approximately 10,000 atoms. Minimization and heating steps were carried out with the restraint option activated and deactivated in the initial stages and the final stages, respectively. The temperature scale used in the heating and dynamics were that of Langevin dynamics, with a collision frequency of $3.0 \mathrm{ps}^{-1}$ at a final temperature of $300 \mathrm{~K}\left(\sim 27^{\circ} \mathrm{C}\right)$. The SHAKE algorithm was employed to constrain the bond length in all hydrogen atoms. The Particle Mesh Ewald method was used to calculate the electrostatic interactions using a cut-off value of $7.0 \AA$ for non-bonded interactions. As such, $100 \mathrm{~ns}$ of MD were produced for each system in the posterior structural analysis of proteins using RMSD.

\section{RESULTS}

The sequences for exons I and II in the $\beta$-defensin II gene found in sheep were determined, and two SNPs stood out; one in position 1643 (A to $G$ ), and the other in position 1659 (G to A). These SNPs are not synonymic as they change isoleucine (I) to valine $(\mathrm{V})$, and arginine $(\mathrm{R})$ to lysine $(\mathrm{K})$, respectively (Figure $1 \mathrm{~A})$.

When compared to the ANOLEA template and graphics with low energy, the three models showed RMSD values of around $1.5 \AA$, indicating high stability of these structures. All models demonstrated a structure with 3 anti-parallel $\beta$-sheets, which are well-preserved between the analyzed sequences. All of the structures contained 6 conserved cysteine residues, forming disulphide bonds similar to the classic $\beta$-defensins, including the G-X-C motif next to the second $\beta$-sheet (Figure 1B). 
A $\beta$-defensin II gene sequence in sheep and SNPs.

- Exon I

ATGAGGCTCCATCACCTGCTCCTCGTGCTCTTCTTCGTGGTCCTGTCTGCTGGGTCAG

- Exon II

GATTIACTCATGGAGTAACAGATAGTCTAAGCTGCCGTTGGAAGAAAGGCATCTGTGTGCTGACCAGGTG

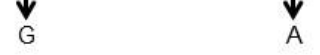

CCCTGGAACCATGAGACAGATTGGCACCTGTTCGGGCCCCCAGTAAAATGCTGCAGACTGAAGTAA

B Amino acid sequences due to SNPs.

- AG - MRLHHLLLVLFFVVLSAGSGFTHGVTDSLSCRWKKGICVLTRCPGTMRQIGTCFGPPVKCCRLK

-AA - MRLHHLLLVLFFVVLSAGSGFTHGVTDSLSCRWKKGICVLTKCPGTMRQIGTCFGPPVKCCRLK

- GG - MRLHHLLLVLFFVVLAGSGFTHGVTDSLSCRWKKGVCVLTRCPGTMRQIGTCFGPPVKCCRLK

C Alignment based from secundary structures.

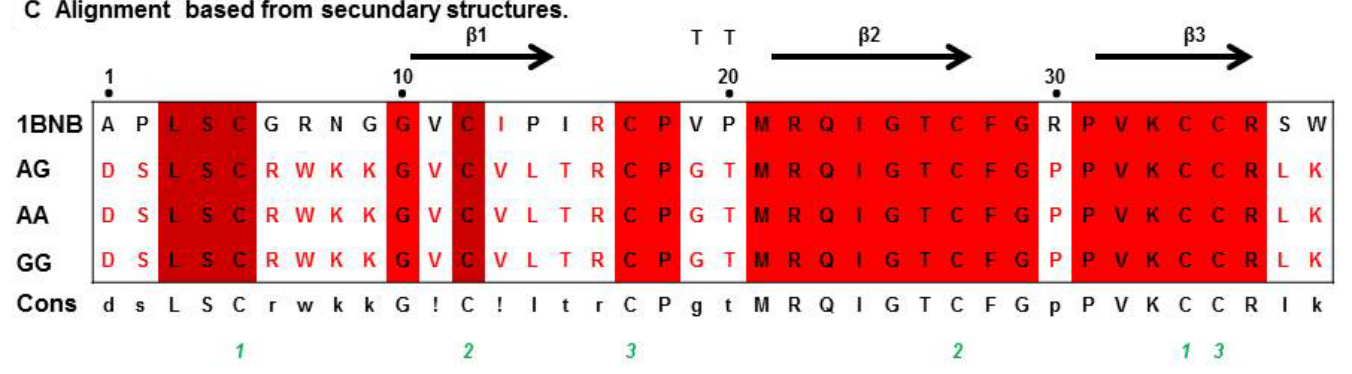

Figure 1. Exon I and II sequences. A. SNPs detected in exon II during sequencing. B. Amino-acid sequences altered as a result of the SNPs. C. Alignment of secondary structure of the models generated by the alleles upon the removal of the peptide signal (AA, AG, GG) when compared to the structure template 1BNB. Disulfide bonds are shown in blue. Sequence alignments were performed with Espript 3.0 (Robert and Gouet, 2014).

In addition to possessing very well-preserved cysteine residues, it is also characteristic of defensins to possess a large number of amino acids such as arginine and lysine, which produce an overall positive charge (McDermott, 2004). In this regard, it is possible to observe a preserved region containing two lysines and one arginine (RWKK) in the first loop of $\beta$-defensins in sheep, which are absent in bovine $\beta$-defensin. This generated a difference in protein charges during the preparation for MD, such that the 1BNB template had a resultant charge of +6 while the rest had a charge of +7 , leading to an increase in protein affinity through the cell membrane.

The four defensins demonstrated different behaviors and charge distributions. 1BNB and AA were the most similar, and deviated the least from the initial structure. They demonstrated the greatest variation in structure only after $60 \mathrm{~ns}$, but remained stable for up to $70 \mathrm{~ns}$. The remaining defensins showed a deviation range of $2 \AA$ from the original structure. On the other hand, the AG and GG forms have a RMSD value of around $3 \AA$, with the largest separation found between the $\beta$-sheets (Figures 2 and 3 ). 


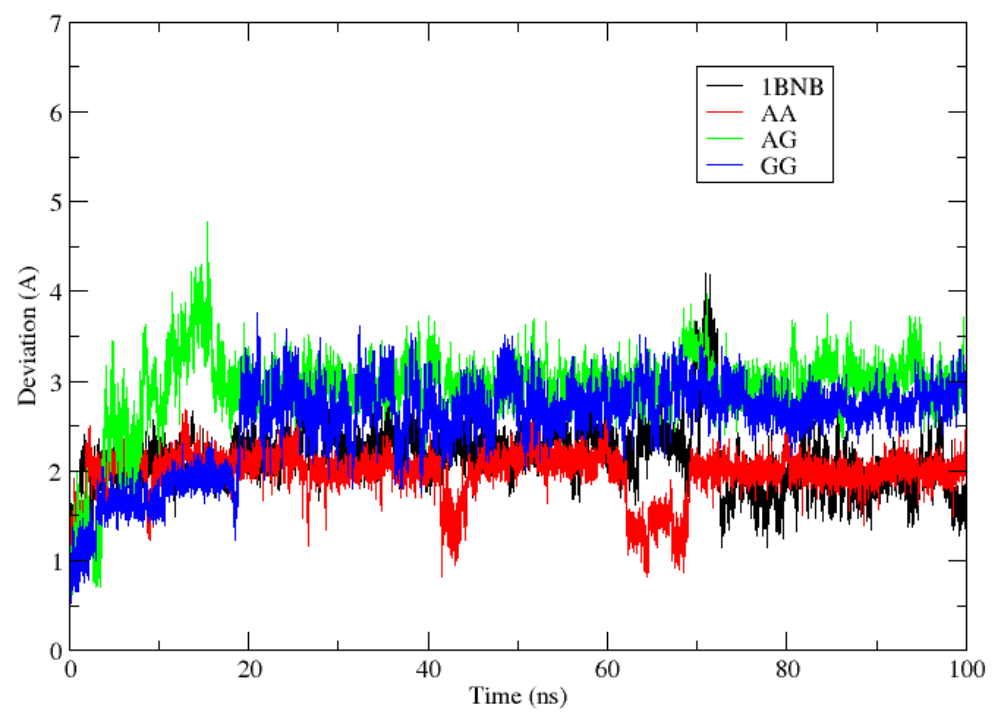

Figure 2. Graphic showing the RMSD (Root Mean Square Deviation) of the defensins during 100 ns of MD.
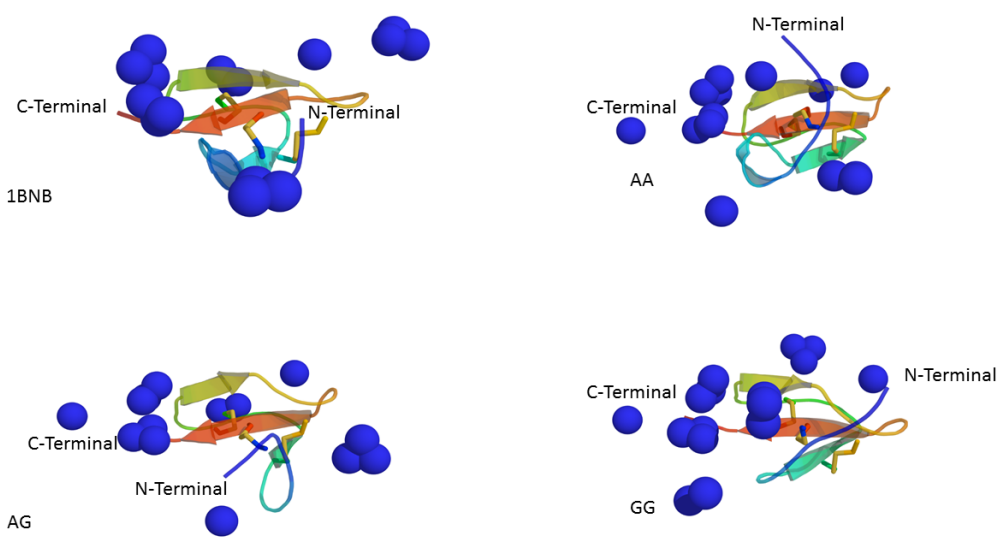

Figure 3. Structures adopted by the four proteins at $50 \mathrm{~ns}$ of MD. Disulphide bonds (sticks) were highlighted; the nitrogen atoms of lysines and arginines are presented as blue spheres.

\section{DISCUSSION}

The models generated in this study were very similar to the structures of classic defensins already described as NP-2, NP-5, HNP1, and HNP-3 (Zimmermann et al., 1995). Furthermore, two points of polymorphism were observed in the extremities of the first $\beta$-sheet. Mutation $V 11$ I was observed in the AA and GG sequences, while the R16K mutation was observed only in the AA sequence when compared with the template, but these mutations do not affect dramatically the structures. 
During the $\mathrm{MD}$, the largest concentration of positive charges were observed in the C-terminus, with the exception of the AG variant, which demonstrated the largest distribution of positive charges. In addition, the $\beta$-sheets had smaller fluctuation as compared to the loop regions, with the first loop of the GG allele demonstrating the largest fluctuation.

Polarization of the charges in the tertiary structure is important for the activity of the $\beta$-defensins. The $\mathrm{C}$-terminus portion usually contains a large concentration of positive charges while the $\mathrm{N}$-terminal portion contains hydrophobic residues, creating a cationic/hydrophobic organization (Zimmermann et al., 1995). We observed that the AA, AG, and GG alleles in sheep demonstrated a large positive charge due to a larger quantity of arginine and lysine residues when compared to the bovine template. Among them, the GG allele best demonstrated a cationic/hydrophobic state in the MD trajectory.

\section{Conflicts of interest}

The authors declare no conflicts of interest.

\section{ACKNOWLEDGMENTS}

We would like to thank Universidade Federal do Pará (Federal University of Pará) for providing the computer systems, including the software licences needed to carry out this investigation; Centro de Pesquisa de Caprinos e Ovinos do Pará (Centre for Caprine and Ovine Research of Pará) for granting us the animal blood samples; and Fundação Amazônia de Amparo a Estudos e Pesquisas do Pará (FAPESPA) for financially supporting the project (process ICAAF \#099/2014).

\section{REFERENCES}

Arnold K, Bordoli L, Kopp J and Schwede T (2006). The SWISS-MODEL workspace: a web-based environment for protein structure homology modelling. Bioinformatics 22: 195-201.http://dx.doi.org/10.1093/bioinformatics/bti770

Berman HM, Westbrook J, Feng Z, Gilliland G, et al. (2000). The protein data bank. Nucleic Acids Res. 28: 235-242.http:// dx.doi.org/10.1093/nar/28.1.235

Case D, Darden T, Cheatham T, Simmerling C, et al. (2012). AMBER 12.

Casseb A do R, Casseb LMN, da Silva SP and Vasconcelos PF da C (2013). Arbovírus: importante zoonose na amazônia brasileira. Vet. Zootec. 20: 391-403.

Eswar N, Webb B, Marti-Renom MA, Madhusudhan MS, et al. (2006). Comparative protein structure modeling using Modeller. Curr. Protoc. Bioinformatics 2 (2.9).

Huttner KM, Brezinski-Caliguri DJ, Mahoney MM and Diamond G (1998a). Antimicrobial peptide expression is developmentally regulated in the ovine gastrointestinal tract. J. Nutr. 128 (Suppl): 297S-299S.

Huttner KM, Lambeth MR, Burkin HR, Burkin DJ, et al. (1998b). Localization and genomic organization of sheep antimicrobial peptide genes. Gene 206: 85-91.http://dx.doi.org/10.1016/S0378-1119(97)00569-6

Janeway CA, Jr. and Medzhitov R (2002). Innate immune recognition. Annu. Rev. Immunol. 20: 197-216.http://dx.doi. org/10.1146/annurev.immunol.20.083001.084359

Laube DM, Yim S, Ryan LK, Kisich KO, et al. (2006). Antimicrobial peptides in the airway. Curr. Top. Microbiol. Immunol. 306: 153-182.http://dx.doi.org/10.1007/3-540-29916-5 6

McDermott AM (2004). Defensins and other antimicrobial peptides at the ocular surface. Ocul. Surf. 2: 229-247.http://dx.doi. org/10.1016/S1542-0124(12)70111-8

Monteleone G, Calascibetta D, Reina R and Portolano B (2010). Study of $\beta$-defensin polymorphisms in Valle del Belice dairy sheep. Ital. J. Anim. Sci. 1: 111. http://dx.doi.org/10.4081/ijas.2009.s2.111

Monteleone G, Calascibetta D, Scaturro M, Galluzzo P, et al. (2011). Polymorphisms of $\beta$-defensin genes in Valle del Belice dairy sheep. Mol. Biol. Rep. 38: 5405-5412.http://dx.doi.org/10.1007/s11033-011-0694-5 
Petersen TN, Brunak S, von Heijne G and Nielsen H (2011). SignalP 4.0: discriminating signal peptides from transmembrane regions. Nat. Methods 8: 785-786.http://dx.doi.org/10.1038/nmeth.1701

Robert X and Gouet P (2014). Deciphering key features in protein structures with the new ENDscript server. Nucleic Acids Res. 42: W320-W324.http://dx.doi.org/10.1093/nar/gku316

Selsted ME and Ouellette AJ (2005). Mammalian defensins in the antimicrobial immune response. Nat. Immunol. 6: 551-557. http://dx.doi.org/10.1038/ni1206

Soehnlein O (2009). Direct and alternative antimicrobial mechanisms of neutrophil-derived granule proteins. J. Mol. Med. 87: 1157-1164.http://dx.doi.org/10.1007/s00109-009-0508-6

Souza BB, Barbosa EM, Azevedo JSN, Campelo JEG, et al. (2015) Genetic polymorphisms in $\beta$-defensin II gene in Amazon sheep from Brazil. Genet. Mol. Res. 14: 12805-12810.

Tang M and Hong M (2009). Structure and mechanism of beta-hairpin antimicrobial peptides in lipid bilayers from solid-state NMR spectroscopy. Mol. Biosyst. 5: 317-322.http://dx.doi.org/10.1039/b820398a

Zhao L and Lu W (2014). Defensins in innate immunity. Curr. Opin. Hematol. 21: 37-42.http://dx.doi.org/10.1097/ $\mathrm{MOH} .0000000000000005$

Zimmermann GR, Legault P, Selsted ME and Pardi A (1995). Solution structure of bovine neutrophil beta-defensin-12: the peptide fold of the beta-defensins is identical to that of the classical defensins. Biochemistry 34: 13663-13671.http:// dx.doi.org/10.1021/bi00041a048 